\title{
Long term follow-up after sudden withdrawal from a multicentric study of abatacept in juvenile idiopathic arthritis - data from the Portuguese cohort
}

\author{
S Melo Gomes ${ }^{*}$, JA Melo Gomes² \\ From 18th Pediatric Rheumatology European Society (PReS) Congress \\ Bruges, Belgium. 14-18 September 2011
}

\section{Background}

A cohort of patients participating in a multicentric, multinational phase III trial to assess the efficacy and safety of abatacept in juvenile idiopathic arthritis (JIA) were discontinued from the study due to administrative reasons.

\section{Aim}

To assess long term efficacy and monitor clinical follow up after the sudden removal of abatacept.

\section{Methods}

Patients in the open arm of the trial, receiving $10 \mathrm{mg} / \mathrm{kg}$ monthly infusions of abatacept were followed for 4 years after its suspension. Outcome measures included clinical remission and disease control without biologics.

\section{Results}

Eight patients $(7 \mathrm{M} / 1 \mathrm{~F})$ with mean age of 16.5 years (range 13-19years) and disease duration of 8,6years (range 1,5-13years) were followed. All patients had polyarticular involvement only partially responsive to methotrexate (extended oligoarticular (OE)-3, polyarticular Rheumatoid factor IgM negative (Poly)-2, systemic onset (SoJIA)-3). Concurrent therapies, maintained after the abatacept trial included NSAIDS, Methotrexate (8/8) and low dose steroids (3/8).

All patients met the ACRpedi30 criteria, 5 of which (OE and Poly) were either in remission (2/8) or had marked improvement (1or 2 active joints). After 12 months of follow-up, all OE patients had inactive disease, as well as one Poly (4/8). Subsequently, 1of the OE and the other Poly flared, with etanercept being introduced at 27 and 29months of follow-up, respectively; 3 patients currently remain in full remission after 4 years (2 OE, 1 poly).

SoJIA patients maintained active disease, requiring biologic therapy (mean 18months).

\section{Conclusion}

Although it's a small cohort, this study suggests that abatacept may induce long term remission in polyarticular JIA patients, especially EO and Poly subtypes. Similar results were not observed in SoJIA patients.

\section{Author details}

${ }^{1}$ Department of Pediatrics, Centro Hospitalar Oeste Norte, Portugal. ${ }^{2}$ Pediatric Rheumatology Clinic, Instituto Português de Reumatologia, Lisbon, Portugal.

Published: 14 September 2011

\section{doi:10.1186/1546-0096-9-S1-P191}

Cite this article as: Gomes and Gomes: Long term follow-up after sudden withdrawal from a multicentric study of abatacept in juvenile idiopathic arthritis - data from the Portuguese cohort. Pediatric Rheumatology 2011 9(Suppl 1):P191.

* Correspondence: sonia.melo.gomes@gmail.com

1 Department of Pediatrics, Centro Hospitalar Oeste Norte, Portugal

Full list of author information is available at the end of the article 